\title{
MAPEAMENTO E CARACTERIZAÇÃO DAS UNIDADES DE RELEVO DO MUNICÍPIO DE ROSÁRIO DO SUL - RS
}

\author{
Daniélli Flores Dias $^{(\mathrm{a})}$, Romário Trentin ${ }^{(\mathrm{b})}$, Rodrigo Dias Marques ${ }^{(\mathrm{c})}$, Eloisa Penna da Rosa ${ }^{(\mathrm{d})}$ \\ (a) Departamento de Geociências, Universidade Federal de Santa Maria, daniellidias08@gmail.com \\ (b) Departamento de Geociências, Universidade Federal de Santa Maria, romario.trentin@ gmail.com \\ (a) Departamento de Geociências, Universidade Federal de Santa Maria, dinizgeo@gmail.com \\ (b) Departamento de Geociências, Universidade Federal de Santa Maria, eloisapenna@ hotmail.com
}

\section{Eixo: SISTEMA GEOMORFOLÓGICO: ESTRUTURA, DINÂMICAS E PROCESSOS}

\begin{abstract}
Resumo
O presente trabalho tem como objetivo realizar um mapeamento e uma breve caracterização das formas de relevo, utilizando como recorte espacial o limite do município de Rosário do Sul. A definição das unidades de relevo realizou-se com o intuito de individualizar as áreas com determinadas caracteristicas homogêneas, considerando a análise combinada dos atributos referentes a hipsometria, declividade e o comprimento das vertentes analisados através dos perfis topográficos. Com base nisso, utilizou-se como referência a proposta de classificação do relevo do Instituto de Pesquisas Tecnológicas (IPT, 1981) e diante disso foram definidas seis unidades de relevo para o município de Rosário do Sul: Áreas Planas, Colinas Levemente Onduladas, Colinas Onduladas, Colinas de Altitude, Associação de Morros e Morrotes, Morros e Morrotes Isolados.
\end{abstract}

Palavras chave: Geomorfologia; Planejamento; Relevo; Rosário do Sul.

\section{Introdução}

No decorrer das últimas décadas, o estudo das formas de relevo tem adquirido novas dimensões. Cabral (2014) aponta que o "[...] o relevo como objeto de estudo da geomorfologia é o resultado da atuação das forças antagônicas sintetizadas pelas atividades tectônicas e estruturais e pelos mecanismos morfoclimáticos ao longo do tempo geológico podendo ocorrer de forma simultanea ou sucessiva".

O relevo apresenta uma diversidade de formas e de processos que associados principalmente as caracteristicas geológicas e climáticas predominantes, torna bastante complexa a tarefa de representá-lo em um único documento. Cunha, Mendes e Sanchez (2003) postulam que essas dificuldades podem estar associadas aos diferentes procedimentos técnicos, a escala de trabalho e ao objetivo do pesquisador.

Conforme Ross (1990) as formas de relevo e os processos geomorfológicos possuem grande importância, tanto pelo fato de constituírem o substrato físico sobre o qual se desenvolvem as atividades humanas, como por responderem, muitas vezes de forma agressiva as alterações provocadas por tais atividades. 
Casseti (1994) destaca que o relevo assume um importante papel no processo de ocupação do espaço, fator esse que inclui as propriedades de suporte ou recurso, na qual as modalidades de apropriação respondem pelo comportamento da paisagem e as suas consequências.

Nesse sentido, os parâmetros de relevo representam importantes fatores condicionantes aos processos de dinâmicas superficiais, permititndo, desse modo, levantamentos fundamentais na definição de atividades de planejamento.

Conforme Sccoti (2015), as diferentes formas de avaliar o ambiente modificado pelo homem, permitem o surgimento de inúmeros estudos, sendo muito deles voltados para a interação sociedade/natureza, visando buscar alternativas para um uso racional e ordenado do meio ambiente.

Com base nisso, o presente trabalho tem como objetivo apresentar um mapeamento e uma breve caracterização das formas de relevo, utilizando como recorte espacial o limite municipal de Rosário do Sul. O município de Rosário do Sul (Figura 1) localiza-se na porção sudoeste do Estado do Rio Grande

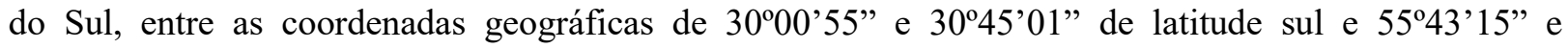
54³7'19” de longitude oeste. De uma forma mais ampla, está inserido na Mesorregião do Sudoese RioGrandense e na Microrregião da Campanha Central, limitando-se com os municípios de Alegrete (a noroeste), Cacequi (ao norte), Dom Pedrito (ao sul), Quaraí (a oeste), Santana do Livramento (a sudoeste) e São Gabriel (a leste).

Conforme os dados do Instituto Brasileiro de Geografia e Estatística (IBGE, 2010) o município possui uma área territorial de $4.369,32 \mathrm{~km}^{2}$, uma população total de 40.773 habitantes e uma densidade demográfica de $9,09 \mathrm{hab} / \mathrm{km}^{2}$. 


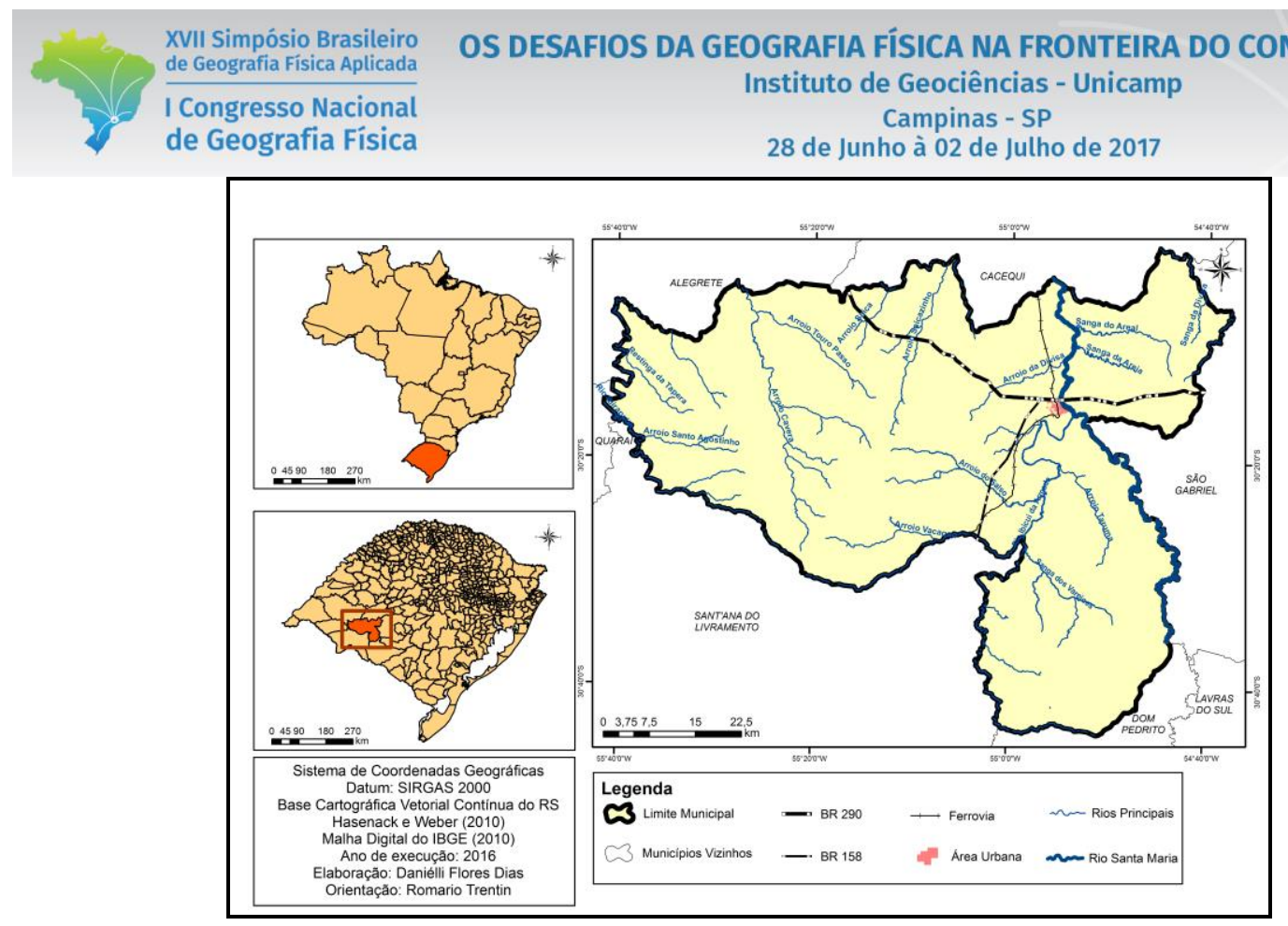

Figura 1 - Localização da área de estudo.

\section{Metodologia}

Para a realização do mapeamento da área de estudo, utilizou-se como base a Malha Digital do IBGE (2010) na escala 1:50.000 que serviu para definir o limite territorial do município de Rosário do Sul; a Base Cartográfica Vetorial Contínua do Estado do Rio Grande do Sul desenvolvida por Hasenack e Weber (2010) na escala 1:50.000, sendo essa base utilizada para identificar a rede hidrográfica da área de estudo; e as Imagens de RADAR da missão SRTM com resolução espacial de 90 metros e que serviram como base para a elaboração do Modelo Digital de Elevação (MDE) da área de estudo.

O estudo topográfico de Rosário do Sul foi realizado a partir da análise do MDE que possibilitou estipular cinco classes hipsométricas representadas em altitudes: <120 metros, entre 120 e 160 metros, entre 160 e 200 metros, entre 200 e 250 metris e > 250 metros.

Com relação as declividades, foram definidas quatro classes que melhor retratassem o comportamento das vertentes na área de estudo. Diante disso, foram estipuladas as seguintes classes de declividades: $<2 \%$, entre $2 \%$ e $5 \%$, entre $5 \%$ e $15 \%$ e $>15 \%$, que seguem a proposta de classificação estabelecida pelo Instituto de Pesquisas Tecnológicas de São Paulo (IPT, 1981) e que são caracterizadas na Tabela 1.

Tabela 1 - Caracterização das classes de declividade propostas pelo IPT.

\begin{tabular}{cl}
\hline Classe & \multicolumn{1}{c}{ Características } \\
\hline $\mathbf{2 \%}$ & $\begin{array}{l}\text { Áreas muito planas e, quando próximas as drenagens, estão sujeitas à ocorrência de } \\
\text { inundações. }\end{array}$ \\
\hline
\end{tabular}




$\begin{aligned} & \text { XVII Simpósio Brasileiro } \\ & \text { de Geografia Física Aplicada }\end{aligned}$
$\begin{aligned} & \text { I Congresso Nacional } \\ & \text { de Geografia Física }\end{aligned}$

\begin{tabular}{cl}
\hline $\mathbf{5 \%}$ & $\begin{array}{l}\text { Área de baixa declividade e onde se registram os processos deposicionais. A partir dessa } \\
\text { inclinação, os processos erosivos passam a ser mais significativos. }\end{array}$ \\
\hline $\mathbf{1 5 \%}$ & $\begin{array}{l}\text { Faixa que define o limite máximo para o emprego da mecanização na agricultura, além de } \\
\text { serem áreas propícias à ocorrência dos processos de movimentos de massa. }\end{array}$ \\
\hline
\end{tabular}

Fonte: De Nardin (2009), adaptado do IPT (1981).

A definição das unidades de relevo do município de Rosário do Sul, realizou-se com o intuito de individualizar as áreas com determinadas características de homogeneidade, considerando a análise combinada dos atributos morfométricos da área de estudo: hipsometria, declividade e comprimento das vertentes analisadas através de perfis topográficos.

Com base nisso, utilizou-se como referência a proposta de classificação do relevo do Instituto de Pesquisas Tecnológicas (IPT, 1981), conforme representa a Tabela 2, sendo essa proposta modificada e adaptada seguindo algumas particularidades do relevo da área de estudo.

Tabela 2 - Classificação das formas de relevo conforme o Instituto de Pesquisas Tecnológicas e adaptadas para a área de estudo.

\begin{tabular}{ccc}
\hline Amplitude Altimétrica & Declividade & Formas de Relevo \\
\hline \multirow{3}{*}{$<100$ metros } & $<2 \%$ & Áreas Planas \\
\cline { 2 - 3 } & $2-5 \%$ & Colinas Suaves \\
\cline { 2 - 3 } & $5-15 \%$ & Colinas \\
\cline { 2 - 3 } & $>15 \%$ & Morrotes \\
\hline$>100$ metros & $>15 \%$ & Morros \\
\hline
\end{tabular}

Fonte: IPT (1981).

A elaboração do mapa de unidades de relevo do município de Rosário do Sul, realizou-se a partir do processo de vetorização manual, onde foram subrepostos os layers de hipsometria e declividade e, além disso, contando tambem com o auxílio dos perfis topográficos, das curvas de nível, pontos cotados e a rede visual das imagens de satélite disponibilizadas pelo serviço Basemap - World Imagery do ArcGIS ${ }^{\circledR}$ 10.1 e também pelo software Google Earth Pro.

Com base nisso, foram definidas as seguintes unidades de relevo para a área de estudo: Áreas Planas, Colinas Levemente Onduladas, Colinas Onduladas, Colinas de Altitude, Associação de Morros e Morrotes e Morros e Morrotes Isolados. Nesse mesmo mapa, foram traçados alguns perfis topográficos que demonstram o comportamento do relevo da área de estudo, além da demarcação de algumas cornijas, que são bastante comuns na região oeste do Rio Grande do Sul.

Com relação aos perfis topográficos, destaca-se que esses foram traçados com o objetivo de determinar a amplitude e o comprimento das vertentes das unidades de relevo identificadas no município de Rosário 


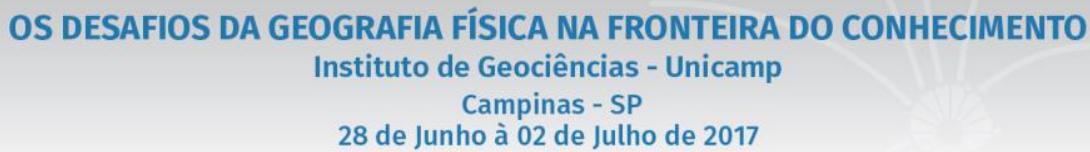

do Sul. Para a elaboração dos mesmos, utilizou-se as ferramentas Interpolate Line e Profile Graph disponíveis no modulo 3D Analyst do ArcGIS 10.1.

Por fim, ocorreu o agrupamento das classes vetorizadas no município, através da utilização da ferramenta Dissolve disponivel no software ArcGIS 10.1 e posterior a isso, as classes de relevo foram quantificadas.

\section{Resultados e Discussões}

O município de Rosário do Sul localiza-se em uma área de transição entre a Depressão Periférica e o Planalto da Campanha. A área de estudo apresenta como menor cota altimétrica o valor de 83 metros, que localiza-se junto ao Rio Santa Maria e como maior cota altimétrica o valor de 363 metros, localizado junto a Serra do Caverá, resultando assim em uma amplitude altimétrica de 280 metros. A Figura 2 representa a distribuição espacial das classes hipsométricas do município de Rosário do Sul.

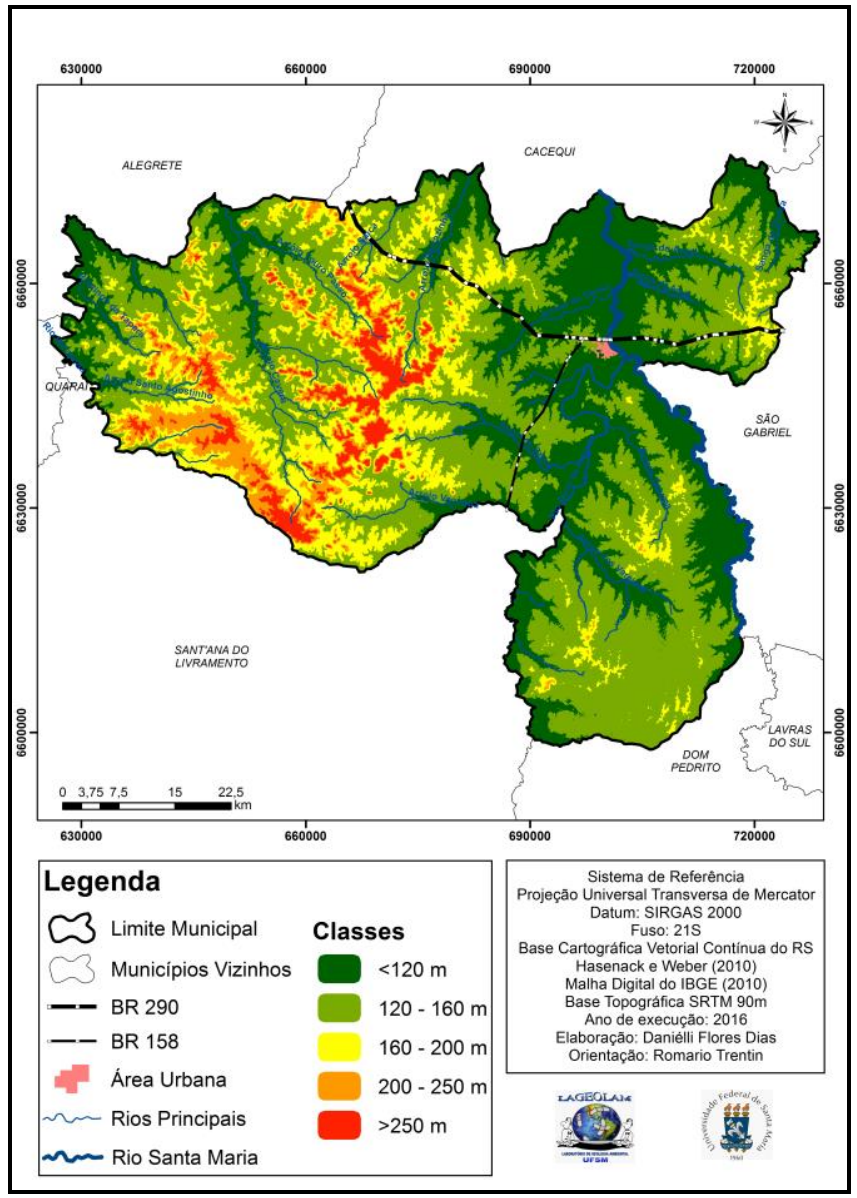

Figura 2 - Distribuição das classes hipsométricas da área de estudo. 
A classe hipsométrica das altitudes inferiores a 120 metros representa 29,83\% do total da área de estudo e abrange porções do extremo leste e oeste do município, em algumas porções ao norte e ao sul, mas com maior expressividade na porção centro-oeste, estando diretamente associadas aos segmentos fluviais de maior hierarquia fluvial. Destaca-se ainda que é nessa classe hipsométrica que localiza-se a área urbana do município de Rosário do Sul.

A classe das altitudes entre 120 e 160 metros representa $45,84 \%$ do total da área do município, constituindo a classe hipsométrica mais expressiva da área de estudo. Essa classe abrange porções do centro, leste e oeste, mas com maior expressividade na porção sul do município e associa-se aos segmentos fluviais de média ordem.

A classe hipsométrica representada pelas altitudes entre 160 e 200 metros corresponde a 15,11\% e abrange porções ao sul e a nordeste da área de estudo, porém com maior expressividade na porção oeste do municipio, demarcando os divisores de água das sub-bacias localizadas na porção centro-oeste de Rosário do Sul.

A classe correspondente as altitudes entre 200 e 250 metros representa 5,82\% do total da área do município e abrange algumas porções no noroeste e no sul, porém com maior expressividade nas porções sudoeste e oeste, demarcando o início da Serra do Caverá.

Por fim, a classe hipsométrica com altitudes superiores a 250 metros representa 3,40\% da área do município, constituindo assim, a classe com menor expressividade na área de estudo. Essa classe abrange porções no centro-oeste e sudoeste que correspondem a Serra do Caverá.

Com relação as declividades do município de Rosário do Sul (Figura 3), destaca-se que o estudo das mesmas tem por objetivo avaliar a inclinação das vertentes, representando um importante parâmetro na identificação das potencialidades e suscetibilidades de uma determinada área, vinculando-se aos processos de dinâmica recorrentes, como a deposição, erosão e os movimentos de massa. 


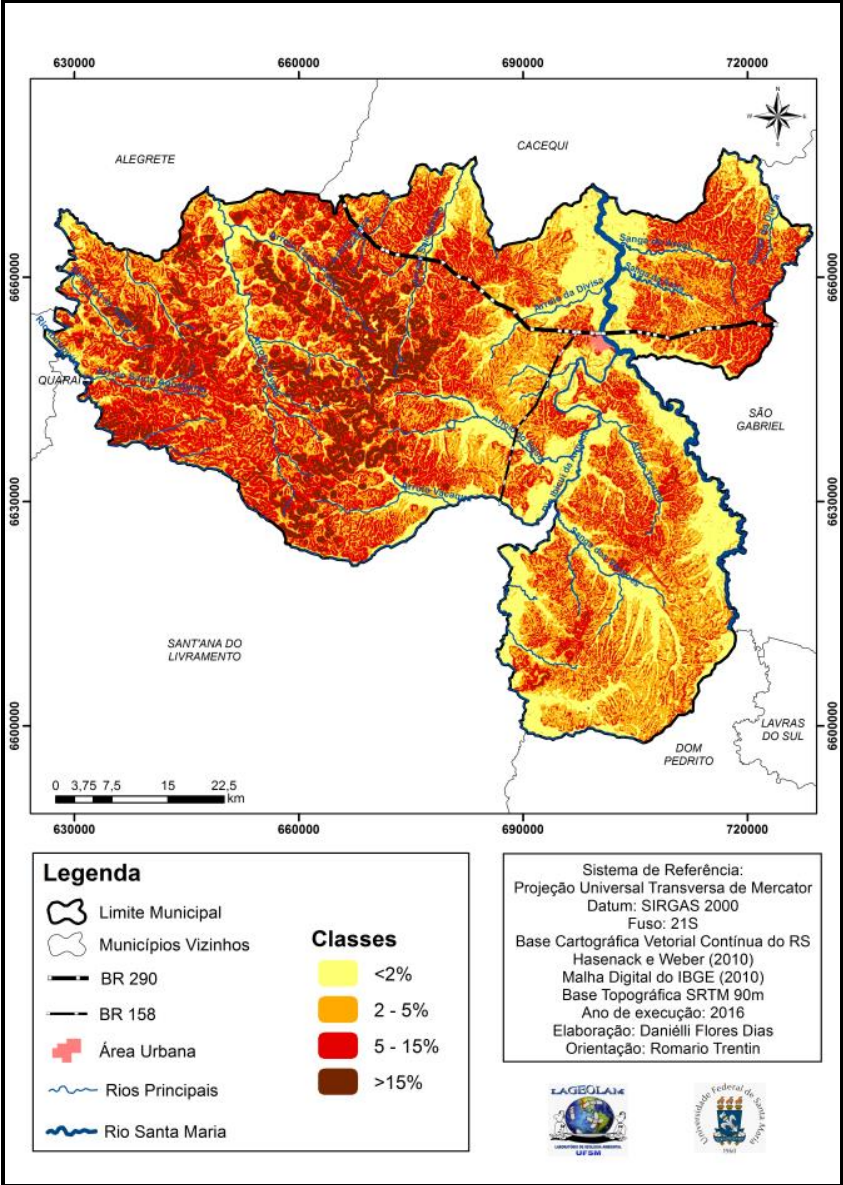

Figura 3 - Distribuição das classes de declividade do município de Rosário do Sul.

A classe das declividades inferiores a $2 \%$ representa $28,19 \%$ do total da área de estudo e distribui-se nas porções sudoeste, nordeste, sul, norte e no extremo oeste do município. Apresenta-se associada aos canais principais da área de estudo, as planícies de inundação e as vertentes levemente onduladas.

As declividades entre 2 e 5\% representam 33,16\% do total da área de estudo, sendo a classe de declividade mais expressiva em Rosário do Sul. Distribui-se nas porções nordeste, norte e sudoeste, nas terras drenadas pelo Arroio Caverá, Arroio Saicã e Sanga do Areal, tendo o uso da terra destinado principalmente para as atividades agropastoris.

A classe de declividades entre 5 e $\mathbf{1 5 \%}$ corresponde a 32,95\% do total da área de estudo e distribui-se nas porções centro-oeste, nordeste e oeste. Apresenta um relevo levemente ondulado e por vezes mais ondulado, com uso da terra destinado as atividades agropastoris.

Por fim, a classe das declividades superiores a $\mathbf{1 5 \%}$ abrange 5,70\% do total da área de estudo, sendo assim, a classe menos expressiva no município de Rosário do Sul. Encontra-se distribuída em uma faixa que corresponde a porção noroeste-sudoeste, além de algumas porções no sudeste da área de estudo. Na Serra do Caverá, predomina um relevo fortemente ondulado, marcado por vertentes íngremes e mais 


\section{OS DESAFIOS DA GEOGRAFIA FÍSICA NA FRONTEIRA DO CONHECIMENTO \\ Instituto de Geociências - Unicamp \\ Campinas - SP \\ 28 de Junho à 02 de Julho de 2017}

escarpadas, com a presença de vegetação mais silvestre que compõem as matas de encostas, além de ser as áreas das nascentes de alguns sistemas fluviais.

O município de Rosário do Sul apresenta uma grande diversidade com relação as formas de relevo, pois na área de estudo encontra-se desde áreas planas próximo as principais drenagens até morros e morrotes isolados que compoem a Serra do Caverá. Diante disso, foram identificadas e caracterizadas e seis unidades que podem ser visualizadas na Figura 4.

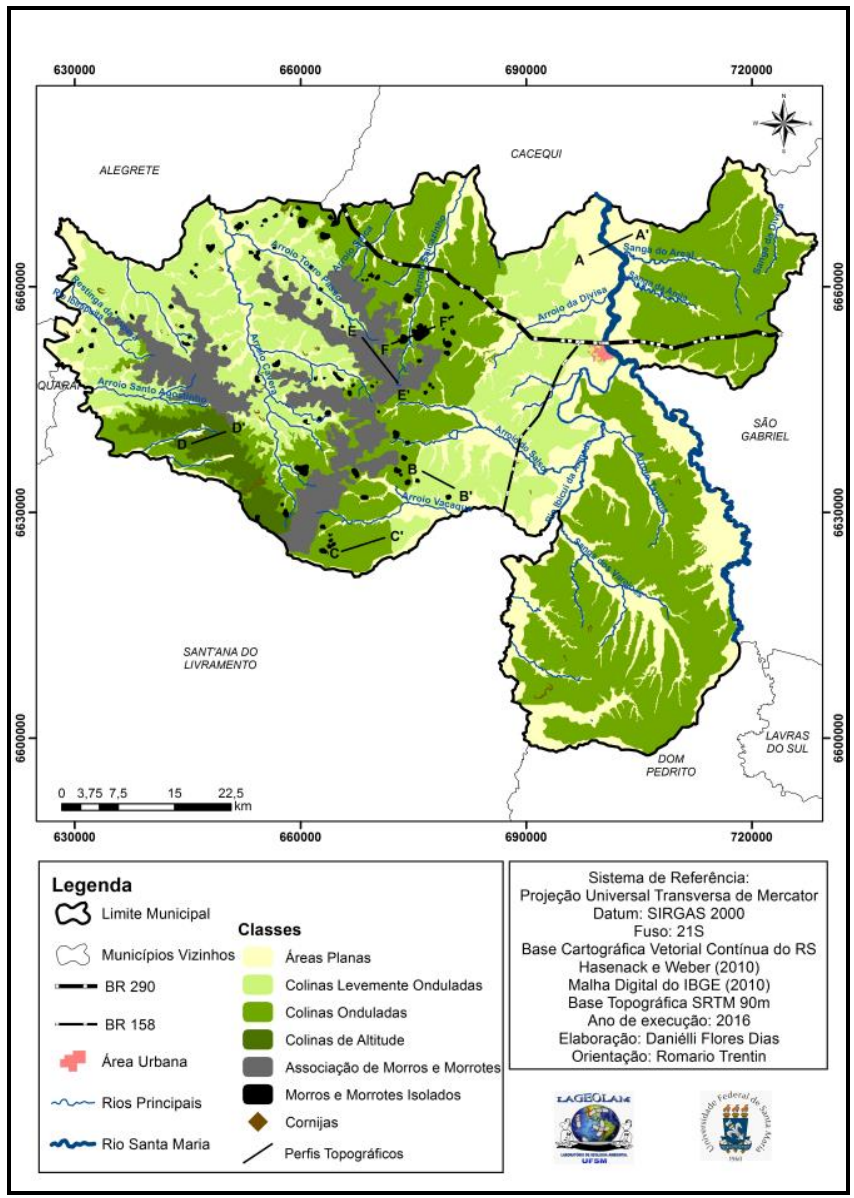

Figura 4 - Distribuição das unidades de relevo no município de Rosário do Sul.

As áreas planas representam $27,11 \%$ do total da área de estudo e caracteriza-se por apresentar altitudes inferiores a 120 metros e declividades menores que 2\%, sendo comumente associada as planícies de inundação e as áreas próximas dos principais afluentes do Rio Santa Maria, onde as litologias são constituídas por depósitos recentes (depósitos aluviais) e os solos são identificados como hidromórficos. Na Figura 5 é possível observar um perfil topográfico traçado na área que corresponde a várzea do Rio Santa Maria e que demonstra o comportamento dessa unidade de relevo no município de Rosário do Sul. 


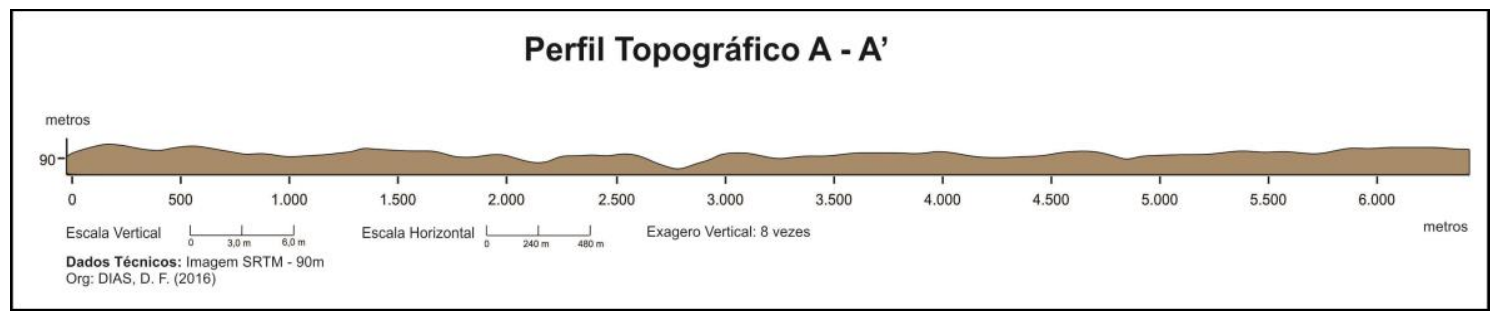

Figura 5 - Representação das áreas planas no município de Rosário do Sul.

A unidade das colinas levemente onduladas representa $20,83 \%$ do total da área do município e caracteriza-se por apresentar altitudes entre 120 e 200 metros, declividades entre 2 e 5\%, interflúvios amplos, litologias constituídas por arenitos e solos predominantemente profundos. Essa forma de relevo é responsável por demarcar o limite em que os processos deposicionais são superados pelos degradacionais, onde ocorre o surgimento de incisões lineares, com sulcos, ravinas e até voçorocas.

Na Figura 6 é possível observar um perfil topográfico traçado na área que corresponde ao divisor de águas do Arroio do Salso e o Arroio Vacaquá, com o intuito de demonstrar o comportamento dessa unidade de relevo no município de Rosário do Sul.

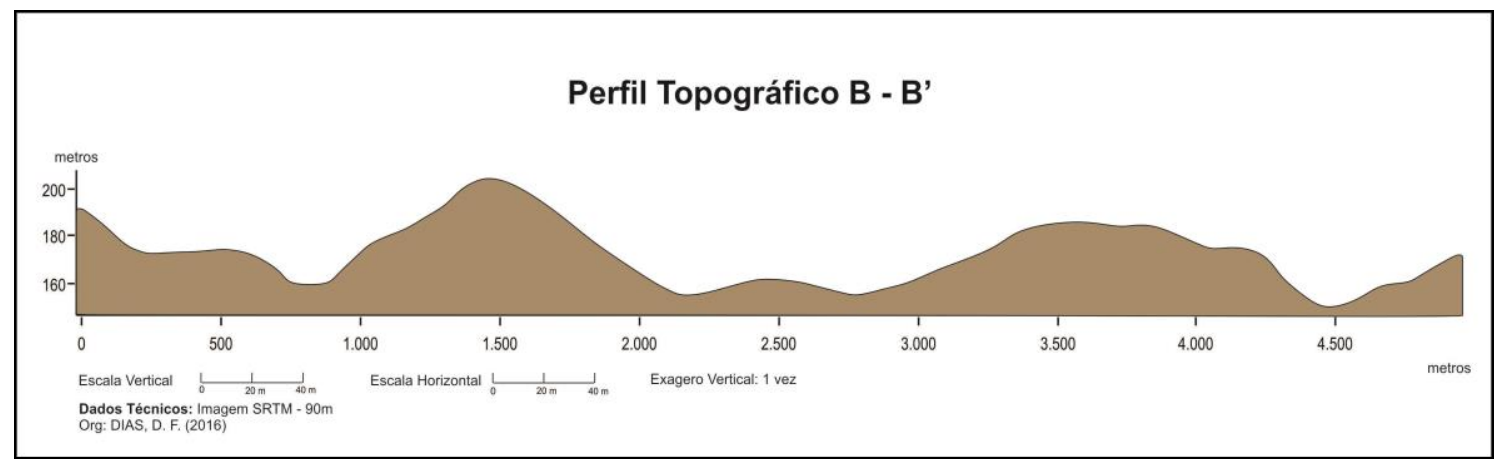

Figura 6 - Representação das colinas levemente onduladas na área de estudo.

Representando 40,39\% do total da área do município de Rosário do Sul, as colinas onduladas é a unidade de relevo com maior expresividade na área de estudo. Caracteriza-se por apresentar altitudes entre 120 e 220 metros, declividades entre 5\% e 15\%, interflúvios curtos, litologias constituídas por arenitos com algumas porções em rochas vulcânicas e solos predominantemente profundos. Essas colinas são responsáveis por marcarem o limite para a mecanização agrícola. 
Na Figura 7 observa-se um perfil topográfico traçado em uma área próxima ao Arroio Vacaquá (porção sudoeste do município), com o objetivo de demonstrar o comportamento dessa unidade de relevo na área de estudo.

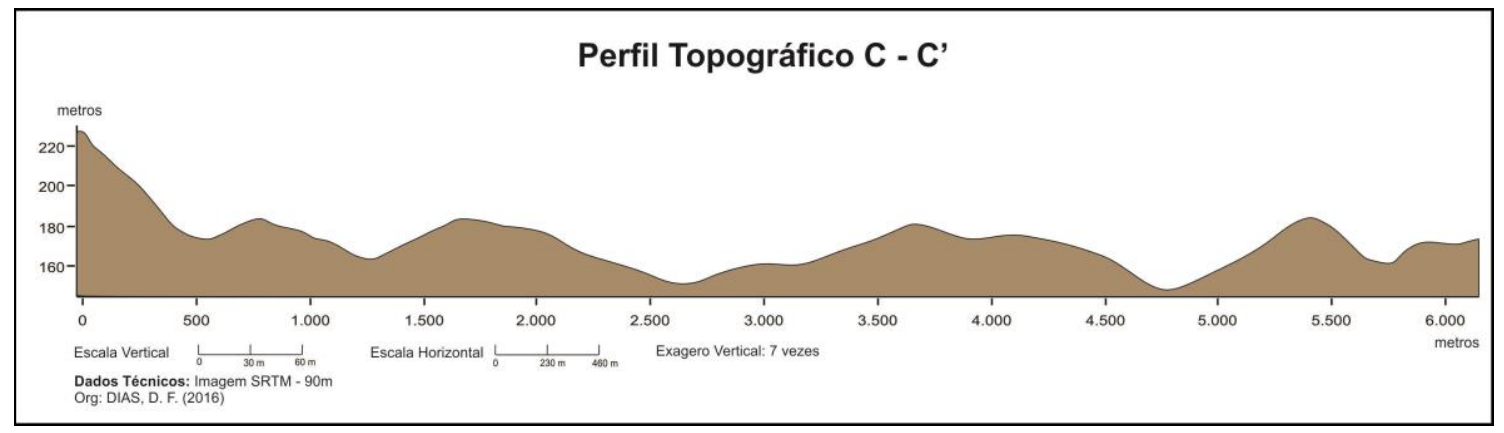

Figura 7 - Representação das colinas onduladas no município de Rosário do Sul.

As colinas de altitude representam $2,36 \%$ do total da área de estudo e caracteriza-se por apresentar altitudes superiores a 200 metros, declividades entre 5 e 15\%, interflúvios curtos, litologias constituidas por rochas vulcânicas e solos rasos.

Na Figura 8 observa-se um perfil topográfico traçado em uma área próxima ao Arroio Três Lagões (porção sudoeste do município), com o objetivo de demonstrar o comportamento dessa unidade de relevo no município de Rosário do Sul.

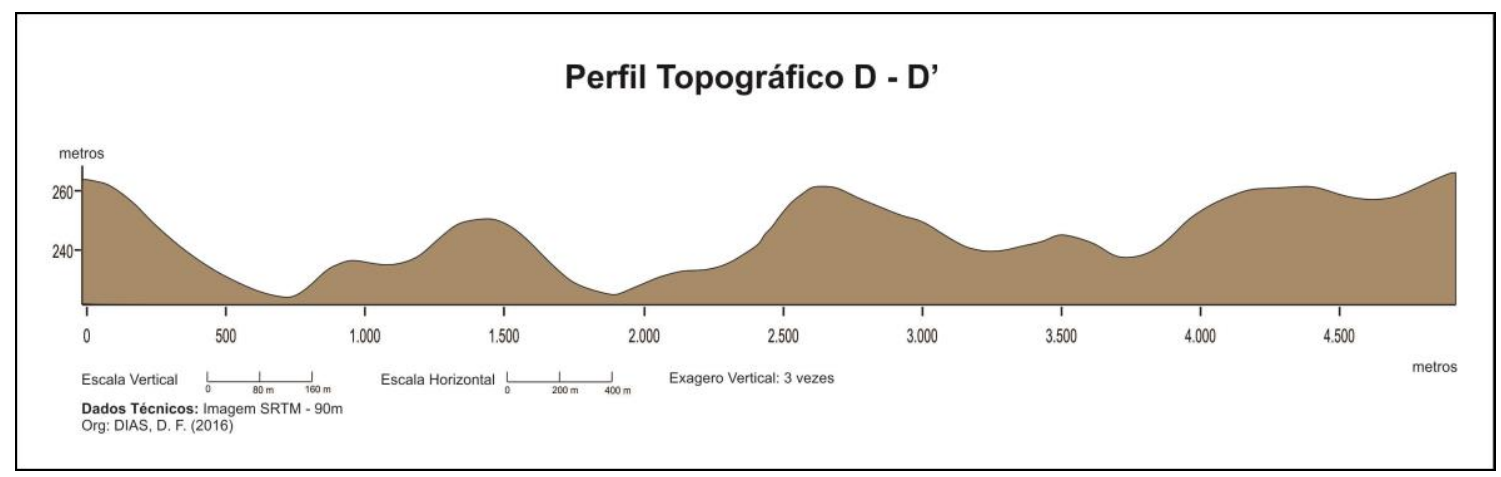

Figura 8 - Representação das colinas de altitude na área de estudo.

A unidade de relevo que corresponde a associação de morros e morrotes representa $8,33 \%$ da área total do município e é constituída principalmente pela Serra do Caverá, que são áreas de grandes elevações que estende-se desde as proximidades da cidade de Alegrete na porção mais a leste, até o município de Santana do Livramento, sendo que alguns autores consideram que a mesma estende-se ainda pelo 


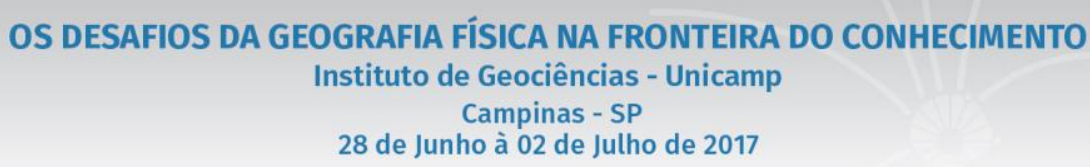

território uruguaio. Caracteriza-se por apresentar altitudes superiores a 200 metros, declividades maiores que $15 \%$, ocupadas por vegetação arbóreo-arbustiva de medio a grande porte, litologias constituídas por rochas vulcânicas e solos rasos.

A Figura 9 representa um perfil topográfico traçado na Serra do Caverá em uma área próxima ao Arroio Saicãzinho e Arroio Touro Passo, demonstrando o comportamento dessa unidade de relevo.

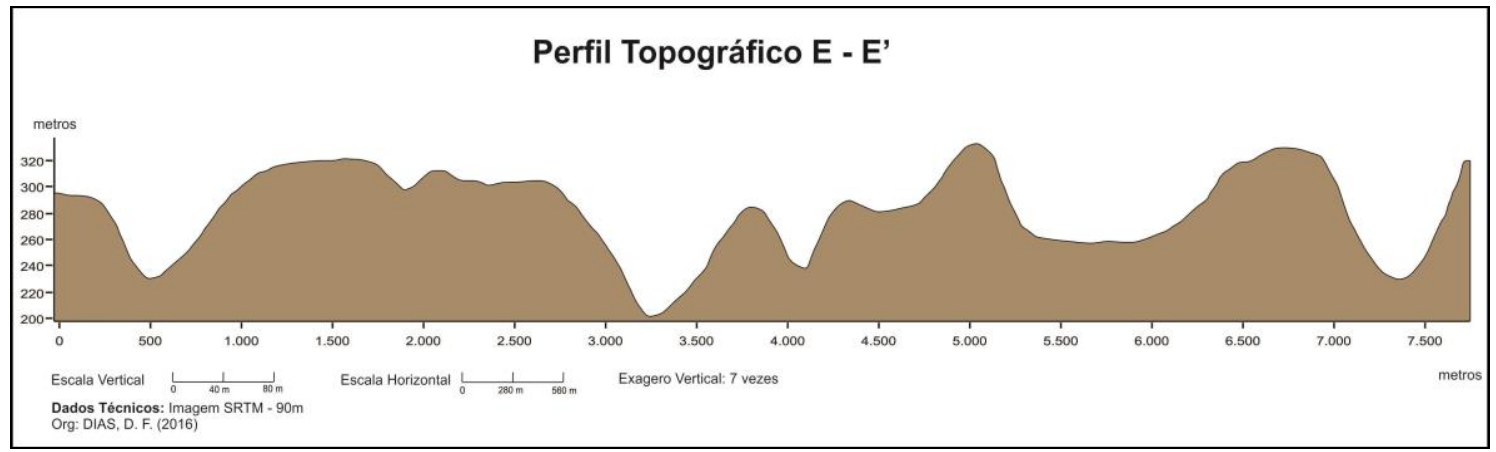

Figura 9 - Representação da associação de morros e morrotes no município de Rosário do Sul.

Por fim, os morros e morrotes isolados representam $0,98 \%$ do total da área de estudo, sendo essa a classe menos expressiva no município. Caracteriza-se por apresentar altitudes superiores a 200 metros e declividades maiores que $15 \%$. Cabe destacar que os morros e morrotes isolados fazem parte da Serra do Caverá, todavia, eles são responsáveis por demarcarem a evolução dos processos erosivos sobre as áreas elevadas topograficamente.

A Figura 10 representa um perfil topográfico traçado em uma área de morros isolados (amplitude altimétrica entre 120 e 140 metros) nas proximidades da Serra do Caverá e do Arroio Saicãzinho.

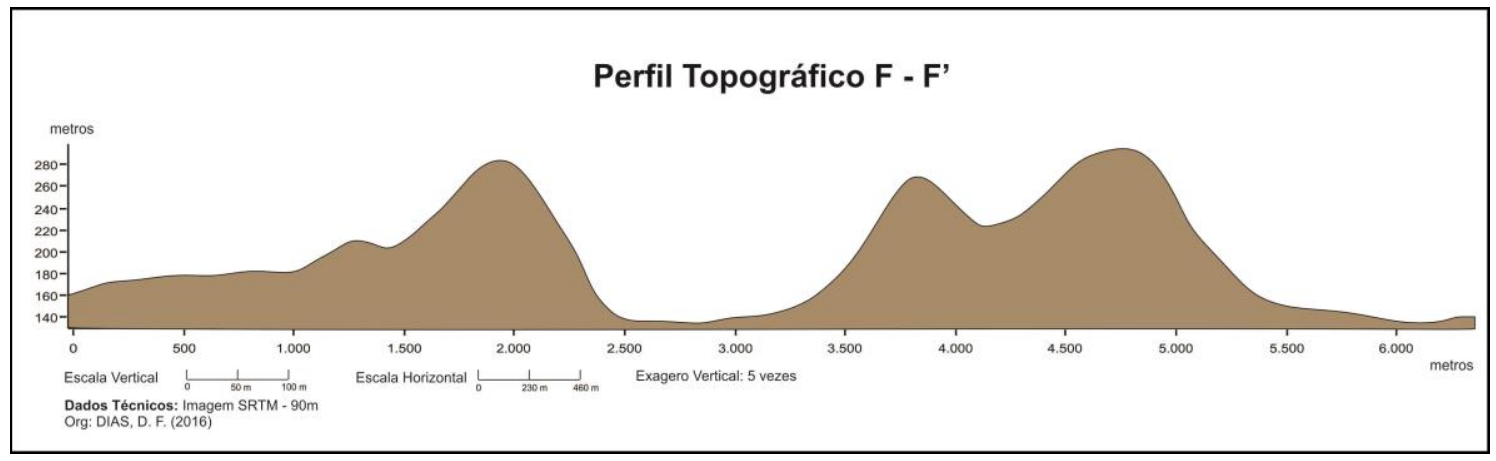

Figura 10 - Representação dos morros e morrotes isolados na área de estudo. 


\section{Considerações Finais}

Esse trabalho descreveu as diferentes formas de relevo que compõem a paisagem da área de estudo e definiu suas principais características quanto a fisiografia e até mesmo, os possíveis processos que possam ser desencadeados, sejam eles naturais ou através da ação antrópica. Dessa forma, além de enriquecer a geomorfologia local, também permitiu contribuir com estudos ligados a dinâmica da sociedade/natureza, sendo que com essas informações é possível ocorrer a tomada de decisão consciente quando se aborda como temática o planejamento e o reordenamento territorial.

Destaca-se ainda que a metodologia e a escala de análise foram satisfatórias, cumprindo com os objetivos e a expectativa esperada. O mapeamento e a caracterização do município de Rosário do Sul permitiu compartimentar a área de estudo em seis unidades de relevo, que foram definidas e mapeadas de acordo com a estrutura espacial dos parâmetros utilizados.

\section{Bibliografia}

CABRAL, T. L. Zoneamento e Mapeamento Geoambiental do município de Sorriso-MT. 2014. 131p. Dissertação (Mestrado em Geografia)-Universidade Federal de Santa Maria, Santa Maria, 2014.

CASSETI, V. Elementos de Geomorfologia. Goiânia: Editora da UFG, 1994. 137p.

CUNHA, C. M. L.; MENDES, I. A.; SANCHEZ, M. C. A Cartografia do Relevo: Uma Análise Comparativa de Técnicas para a Gestão Ambiental. Revista Brasileira de Geomorfologia, São Paulo, v. 4, n. 1, p. 1-9, 2003. Disponível em: <http://www.lsie.unb.br/rbg/index.php?journal=rbg\&page=article\&op=view\&path\%5B $\% 5 \mathrm{D}=15 \&$ path $\% 5 \mathrm{~B} \% 5 \mathrm{D}=$ 13/>. Acesso em: 12 mar. 2016.

ENVIRONMENTAL SYSTEMS RESEARCH INSTITUTE. ArcGIS ${ }^{\circledR}$ 10.1 License Manager and Installation. Disponível em: <http:/desktop.arcgis.com/en/desktop/latest/get-started/license-manager-guide/license-managerinstallation-and-startup.htm/>. Acesso em: 10 mar. 2016.

HASENACK, H.; WEBER, E. Base Cartográfica Vetorial Contínua do Rio Grande do Sul. Série Geoprocessamento, Porto Alegre: Centro de Ecologia da UFRGS, 2010. 1 DVD.

INSTITUTO BRASILEIRO DE GEOGRAFIA E ESTATÍSTICA. Malha Municipal do ano de 2010. Disponível em: <http://mapas.ibge.gov.br/bases-e-referenciais/bases-cartograficas/malhas-digitais>. Acesso em: 18 out. 2015.

INSTITUTO DE PESQUISAS TECNOLÓGICAS. Mapeamento Geomorfológico do Estado de São Paulo. São Paulo. Escala 1:500.000, v. 2, 1981. 130p.

ROSS, J. L. S. Geomorfologia: Ambiente e Planejamento. São Paulo: Editora Contexto, 1990. 88p.

SCCOTI, A. A. V. Zoneamento Geoambiental da Bacia Hidrográfica do Rio Ibicuí da Armada-RS: Potencialidades e Suscetibilidade. 2015. 151p. Dissertação (Mestrado em Geografia)-Universidade Federal de Santa Maria, Santa Maria, 2015.

UNITED STATES GEOLOGICAL SURVEY. Shuttle Radar Topography Mission. Disponível em: <http://srtm.usgs.gov/>. Acesso em: 09 jan. 2016. 